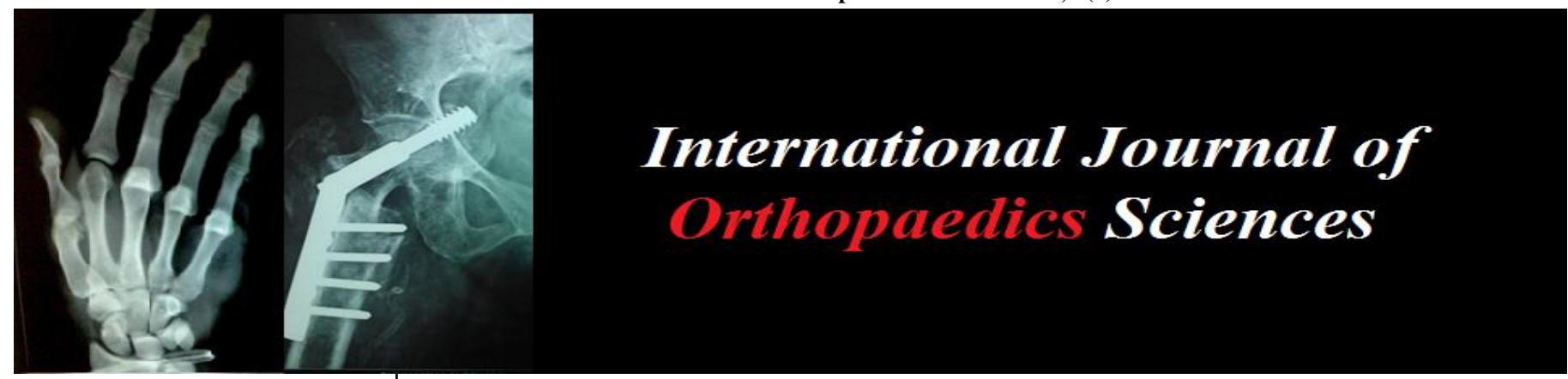

E-ISSN: 2395-1958

P-ISSN: 2706-6630

IJOS 2020; 6(2): 661-665

(C) 2020 IJOS

www.orthopaper.com

Received: 12-02-2020

Accepted: 14-03-2020

Dr. PV Thirumalai Murugan MS Associate Professor, M.S. Ortho. DNB (Ortho)., Madurai Medical College, Madurai, Tamil Nadu, India

Dr. S Sundharrajan MBBS Associate Professor, MBBS. DNB (Neuro Surgery). Madurai Medical College, Madurai, Tamil Nadu, India

Corresponding Author: Dr. S Sundharrajan MBBS Associate Professor, M.S. Ortho. DNB (Ortho)., Madurai Medical College, Madurai, Tamil Nadu, India

\section{Delayed neurological deficit in osteoporotic VCF - surgical outcome}

\section{Dr. PV Thirumalai Murugan MS and Dr. S Sundharrajan MBBS}

DOI: https://doi.org/10.22271/ortho.2020.v6.i2k.2115

\section{Abstract}

Introduction: The International Osteoporosis Foundation has estimated that worldwide, approximately $30 \%-50 \%$ people aged over 50 years are at risk for the development of fragility fractures secondary to osteoporosis. Vertebral compression fractures occur in $20 \%$ of people over the age of seventy years and in $16 \%$ of postmenopausal women.

The majority of fractures heal with conservative treatment after 8 to 10 weeks. Surgery is indicated for patients who present with neurological deficits, deformities, and incapacitating pain with conservative treatment failure. $2 \%$ of patients with OVFs develop cord compression.

This study aimed to identify the clinical presentation and predictors of clinical outcomes among patients operated for delayed neurological deficits after OVFs.

Materials and methods

- 8 cases -5 female, 3 male,

- Dorsolumbar junction - 7 cases, dorsal spine 1 case.

- Neurological status

- ASIA B - 1

ASIA C -5

ASIA D - 2

All cases underwent posterior short segment fixation (pedicle screws one level above and below the fracture vertebra) and percutaneous vertebroplasty and indirect decompression.

Results and analysis: The average time to onset of neurological deficits was 5.4 weeks from the time of injury. Postoperatively neurology improved upto ASIA grade $\mathrm{E}-7$, grade $\mathrm{D}-1$. All patients were followed up with neurological assessment every 2 weeks upto 3 months and every month upto 6 months One patient could not walk, and seven patients walked with heavy assistance. Two patients had sphincter disturbance. The mean preoperative Baba's score was 5.96. The mean values of LAH (lateral anterior vertebral body height) and LPH (lateral posterior vertebral body height) were $41.0 \%$ and $60.7 \%$ postoperatively and $37.4 \%$ and $58.8 \%$ after 6 months post op. The average retropulsion was $36.5 \%$.

Conclusion: Although OVFs are common and generally considered benign, severe and delayed neurological deficits can occur following spinal cord compression. Improved clinical outcomes are associated with compression fractures, less initial retropulsion, lack of surgical complications, and an optimal restoration of retropulsion.

Keywords: Delayed neurological deficit VCF - surgical osteoporosis foundation

\section{Introduction}

The International Osteoporosis Foundation has estimated that worldwide, approximately 30\%$50 \%$ people aged over 50 years are at risk for the development of fragility fractures secondary to osteoporosis. Vertebral compression fractures occur in $20 \%$ of people over the age of seventy years and in $16 \%$ of postmenopausal women.

The majority of fractures heal with conservative treatment after 8 to 10 weeks. Surgery is indicated for patients who present with neurological deficits, deformities, and incapacitating pain with conservative treatment failure. $2 \%$ of patients with OVFs develop cord compression $[1,2]$.

This study aimed to identify the clinical presentation and predictors of clinical outcomes among patients operated for delayed neurological deficits after OVFs. 


\section{Materials and methods}

- 8 cases -5 female, 3 male,

- Dorsolumbar junction - 7 cases, dorsal spine 1 case.

- Neurological status

ASIA B - 1

ASIA C -5

ASIA D - 2

\section{Surgical technique}

7 cases underwent posterior short segment fixation with pedicle screws one level above and one level below the fractured vertebrae and vertebroplasty PMMA cement injected into the vertebral body after taking core biopsy from the body. Indirect decompression done. Postoperatively neurology improved upto ASIA grade $\mathrm{E}-7$, grade D - 1 .
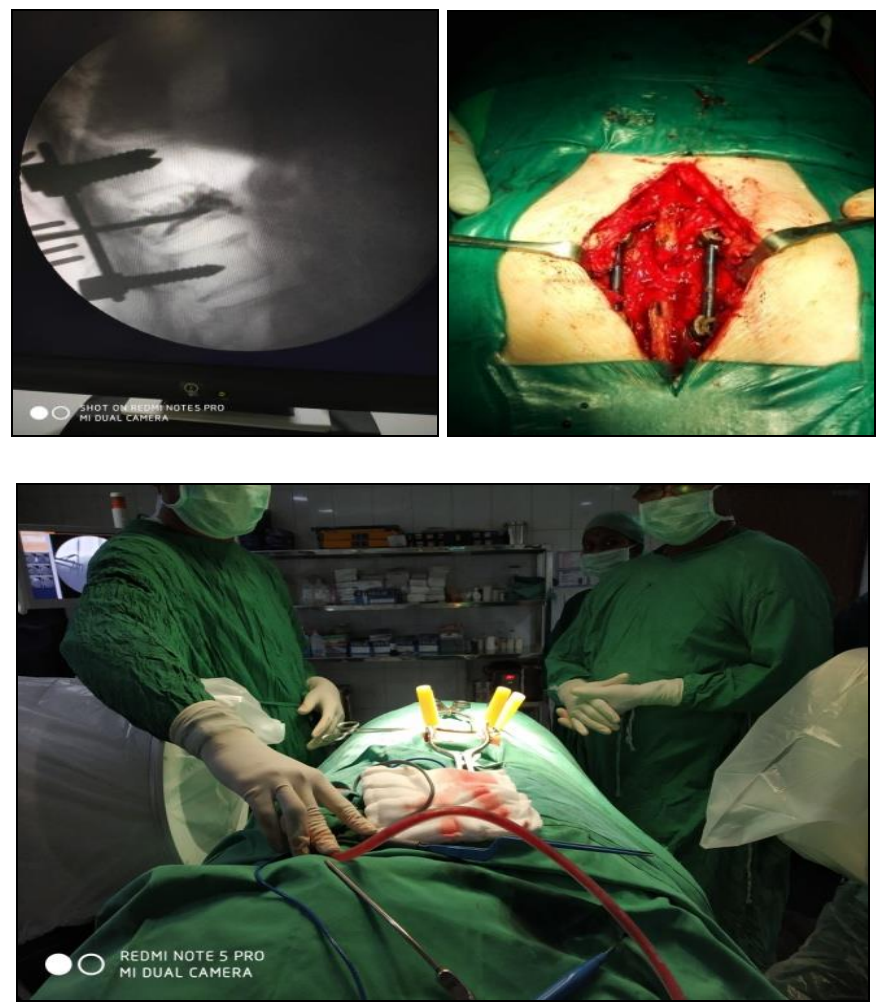

Image 1 \& 2: Showing intraoperative PSF and vertebroplasty

\section{Results and analysis}

The average time to onset of neurological deficits was 5.4 weeks from the time of injury. One patient could not walk, and seven patients walked with heavy assistance. Two patients had sphincter disturbance. The mean preoperative Baba's score was 5.96. The average retropulsion was $36.5 \%$. The mean values of LAH (lateral anterior vertebral body height) and LPH (lateral posterior vertebral body height) were $41.0 \%$ and $60.7 \%$ postoperatively and $37.4 \%$ and $58.8 \%$ after 6 months post op.

\section{Baba Score ${ }^{[3]}$.}

Table 2: Baba pain- neurological scoring system of osteoporotic vertebral fracture (Total score $=14$ )

\begin{tabular}{|c|c|}
\hline Categories & Score (Point) \\
\hline \multicolumn{2}{|l|}{ Spinal pain (3) } \\
\hline Incapacitating and uncontrollable & 0 \\
\hline Controllable with medication & 1 \\
\hline Painful but no medication needed & 2 \\
\hline Negligible or absent & 3 \\
\hline \multicolumn{2}{|c|}{ Motor function of lower extremities (4) } \\
\hline Impossible to walk & 0 \\
\hline Cane or aid on flat ground & 1 \\
\hline Aid only on stairs & 2 \\
\hline Walk unaided but slow & 3 \\
\hline Normal & 4 \\
\hline \multicolumn{2}{|c|}{ Sensory function (2) } \\
\hline \multicolumn{2}{|l|}{ Trunk } \\
\hline Apparent & 0 \\
\hline Minimal & 1 \\
\hline Normal & 2 \\
\hline \multicolumn{2}{|c|}{ Lower extremity (2) } \\
\hline Apparent & 0 \\
\hline Minimal & 1 \\
\hline Normal & 2 \\
\hline \multicolumn{2}{|c|}{ Bladder function (3) } \\
\hline Urinary retention or incontinence & 0 \\
\hline Severe dysuria (sense of retention) & 1 \\
\hline Slight dysuria & 2 \\
\hline Normal & 3 \\
\hline
\end{tabular}

Post-operative improvement rate was calculated as postoperative score minus preoperative score, divided by 14 minus preoperative score, multiple by 100 and shown in percent. Excellent was defined as improvement $>=80$ percent: good 50-79 percent; fair 25-49 percent; and poor <= 24 percent $^{\text {[7] }}$
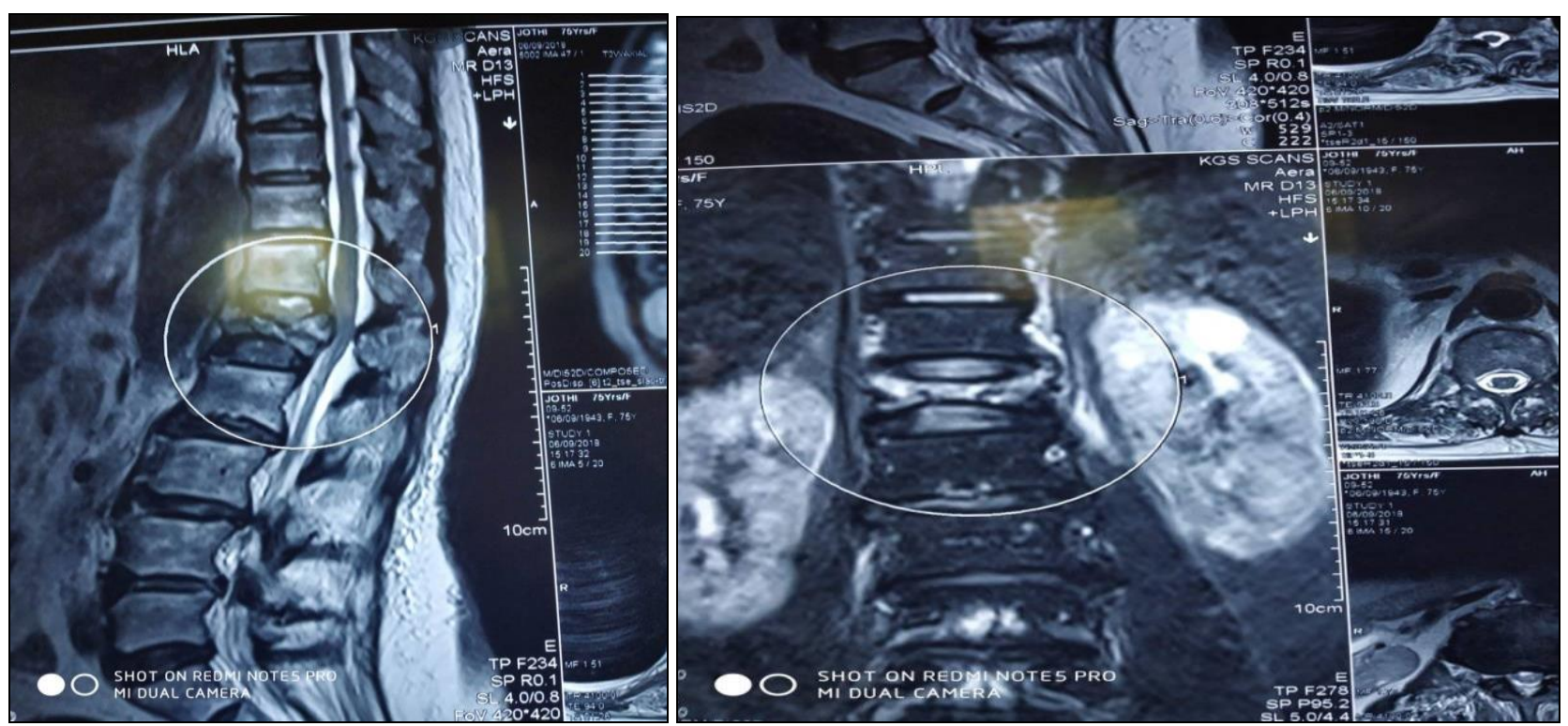

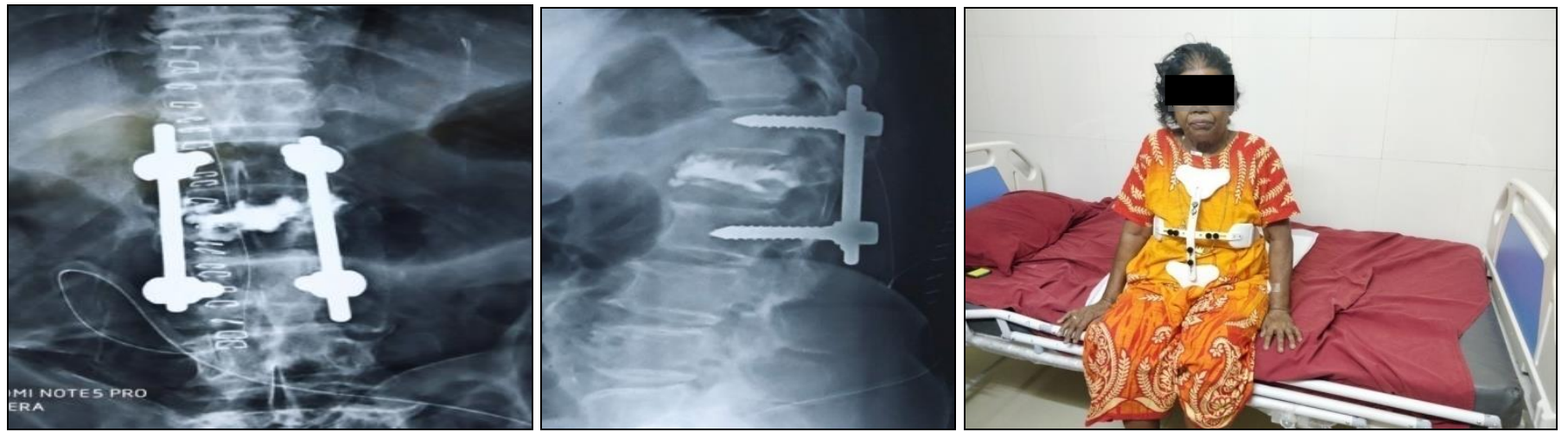

Image 2: Preop and post op picture

\section{Discussion}

OVFs may present as neurological deficits due to spinal cord compression. All patients sustained low-energy injuries.

The natural history of VCF is that $30 \%$ develop further collapse, $13 \%$ go for non-union, and 3\% develop neurological deficit as per Taenichi et al. ${ }^{[4,5]}$

Spinal instability: the concept of spinal instability has been recently introduced in the Osteoporotic VCFs, as these fractures were traditionally considered stable and treated with conservative treatment. However, there are certain risk factors when present make these fractures unstable leading onto a progressive collapse, kyphotic deformity and neurological deficit.

\section{The following were considered as the risk facors.}

1. Middle column burst fractures were suggested to have a higher risk of neurological deficits because of retropulsed fragments ${ }^{[7]}$. In a Japanese series, approximately $91 \%$ of OVFs causing paraplegia were burst fractures ${ }^{[8]}$.

2. Angular instability of $>15^{\circ}$ and retropulsion of $>42 \%$ were predictive factors for neurological deficits ${ }^{[9]}$.

3. Cobb's angle of $>30^{\circ}$ was regarded as a precipitating factor in one study ${ }^{[8]}$, and

4. vacuum sign was observed in 22 patients before the onset of neurological deficits in another study $(n=28)^{[9]}$.
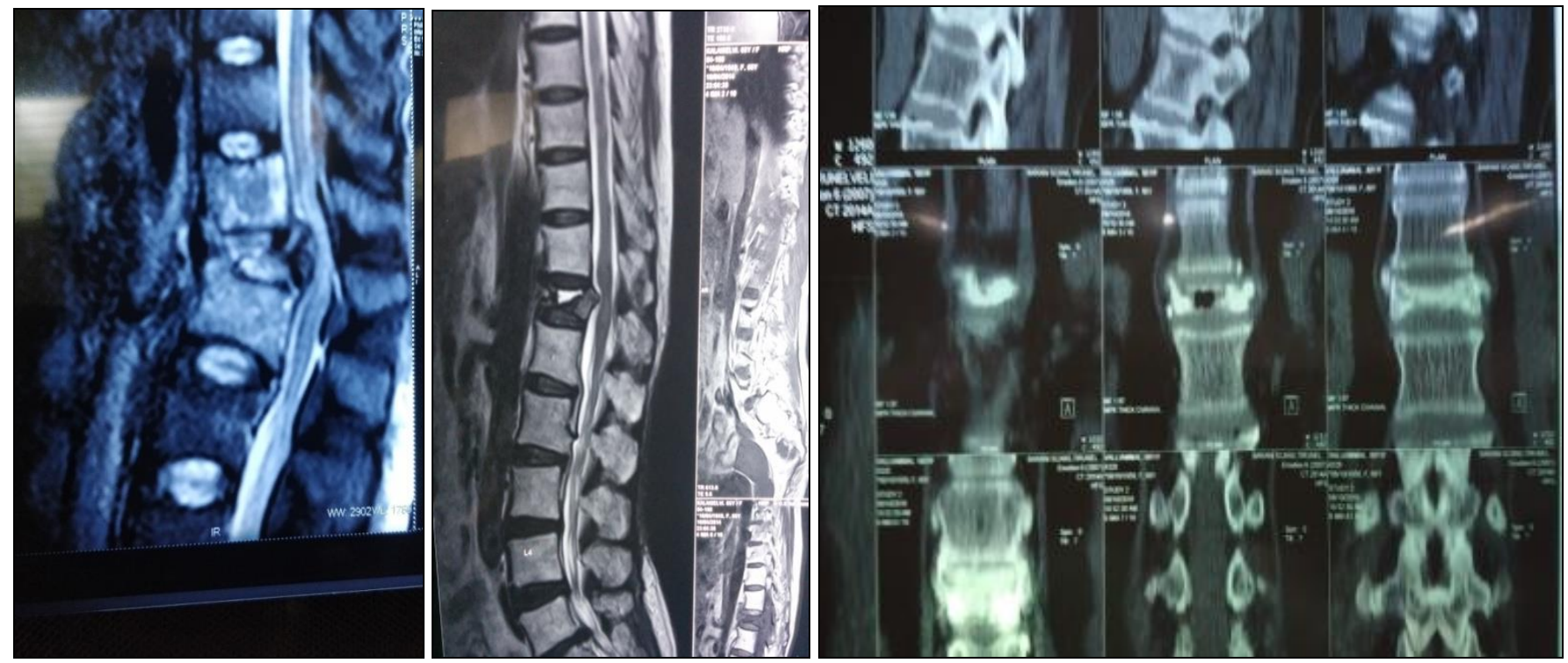

Image 3: Showing risk factors of progression.

The goal of treatmentin these fractures is

1. Neurological decompression,

2. Kyphotic deformity correction,

3. Stable arthrodesed spine.

Surgery in elderly individuals is associated with high complication rate as Nyguen et al. reported a complication rate of $70 \%$, due to Comorbid conditions, and severe osteoporosis, implant purchase very poor.

\section{The surgical procedures available are}

1 Direct anterior decompression and reconstruction.

2 Posterior column shortening osteotomy and stabilisation, and decompression ${ }^{[11]}$.

3 Posterior short segment fixation, decompression and vertebroplasty.

1. Anterior surgery: The advantage of anterior surgery is that decompression is much better and direct. The main disadvantage is the complications of ant. Surgery is as high as $70 \%$

In our series, 7 patients could walk unaided or with a stick at the endpoint following operation.

Sphincter dysfunction and recovery was seldom reported. In one series of 10 patients with paraplegia, only one of four patients with preoperative bowel and bladder incontinence had recovered functional control [21]. In another series of 13 patients with paraplegia, only one patient with urinary incontinence exhibited improvement in urinary function ${ }^{[18]}$. Our finding of sphincter function improvement in seven of 15 
patients may be due to improved mobility and the treatment of urinary tract infection following surgery rather than an actual improvement in neurological function; this is a limitation of our study.

Our study is limited by its retrospective nature, relatively small group of patients, lack of a control group and continuous BMD monitoring, and the diversity of surgeons. Further studies using bone mass monitoring, antiosteoporotic treatment, and advances in surgical technology need to be conducted for examining long-term radiological and clinical outcomes.
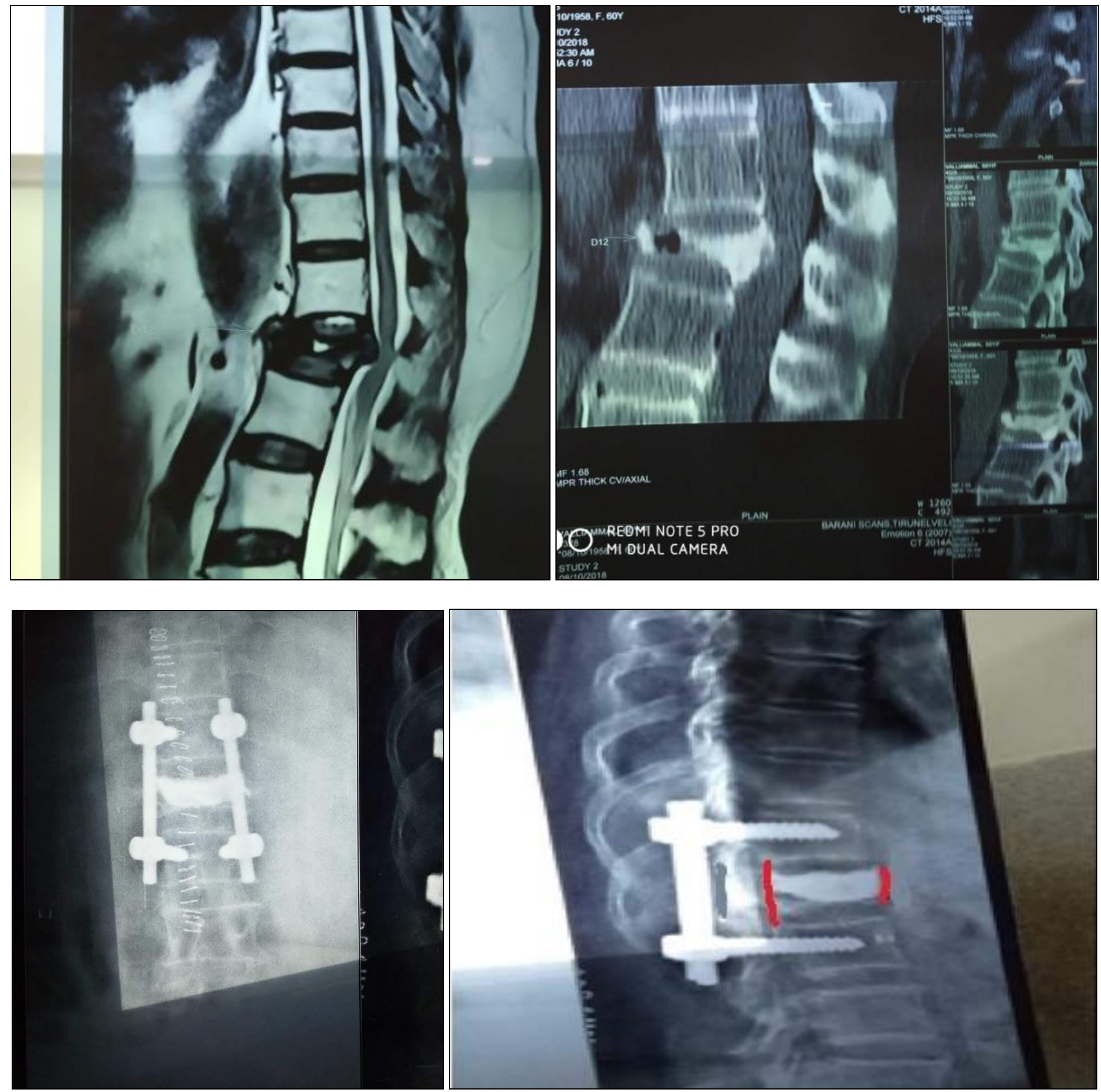

Image 4

\section{Conclusions}

Although OVFs are common and generally considered benign, severe and delayed neurological deficits can occur following spinal cord compression. Improved clinical outcomes are associated with compression fractures, less initial retropulsion, lack of surgical complications, and an optimal restoration of retropulsion.

\section{References}

1. Rousing R, Hansen KL, Andersen MO, Jespersen SM, Thomsen K, Lauritsen JM. Twelve-months follow-up in forty-nine patients with acute/semiacute osteoporotic vertebral fractures treated conservatively or with percutaneous vertebroplasty: a clinical randomized study. Spine (Phila Pa 1976). [PubMed]. 2010; 35:478482.

2. Lee YL, Yip KM. The osteoporotic spine. Clin Orthop Relat Res. [PubMed]. 1996; (323):91-97.

3. Baba H, Maezawa Y, Kamitani K, Furusawa N, Imura S, Tomita K. Osteoporotic vertebral collapse with late neurological complications. Paraplegia. [PubMed]. 1995; 33:281-289. 
4. Kempinsky WH, Morgan PP, Boniface WR. Osteoporotic kyphosis with paraplegia. Neurology. [PubMed]. 1958; 8:181-186.

5. Cortet B, Solau-Gervais E, Labbe P et al. Osteoporotic vertebral crush fractures with severe neurologic manifestations: apropos of 6 cases. Rev Med Interne. [PubMed]. 1995; 16:891-896.

6. Heggeness MH. Spine fracture with neurological deficit in osteoporosis. Osteoporos Int. [PubMed]. 1993; 3:215221.

7. Mori S, Norimatsu H, Oka S. Burst fracture: osteoporotic vertebral compression fracture associated with paraplegia. Nihon Rinsho. [PubMed]. 1994; 52:24352441.

8. Hoshino M, Nakamura $\mathrm{H}$, Terai $\mathrm{H}$ et al. Factors affecting neurological deficits and intractable back pain in patients with insufficient bone union following osteoporotic vertebral fracture. Eur Spine J. [PMC free article] [PubMed]. 2009; 18:1279-1286.

9. Atlas SW, Regenbogen V, Rogers LF, Kim KS. The radiographic characterization of burst fractures of the spine. AJR Am J Roentgenol. [PubMed]. 1986; 147:575582.

10. Ito Y, Hasegawa Y, Toda K, Nakahara S. Pathogenesis and diagnosis of delayed vertebral collapse resulting from osteoporotic spinal fracture. Spine J. [PubMed]. 2002; 2:101-106.

11. Saita K, Hoshino Y, Higashi T, Yamamuro K. Posterior spinal shortening for paraparesis following vertebral collapse due to osteoporosis. Spinal Cord. [PubMed]. 2008; 46:16-20.

12. Kim KT, Suk KS, Kim JM, Lee SH. Delayed vertebral collapse with neurological deficits secondary to osteoporosis. Int Orthop. [PMC free article] [PubMed]. 2003; 27:65-69.

13. Nguyen HV, Ludwig S, Gelb D. Osteoporotic vertebral burst fractures with neurologic compromise. J Spinal Disord Tech. [PubMed]. 2003; 16:10-19.

14. Lee SH, Kim ES, Eoh W. Cement augmented anterior reconstruction with short posterior instrumentation: a less invasive surgical option for Kummell's disease with cord compression. J Clin Neurosci. [PubMed]. 2011; 18:509514.

15. Uchida K, Kobayashi S, Matsuzaki M et al. Anterior versus posterior surgery for osteoporotic vertebral collapse with neurological deficit in the thoracolumbar spine. Eur Spine J. [PubMed]. 2006; 15:1759-1767. 